\title{
Organizational characteristics and restraint use for hospitalized nursing home residents.
}

\author{
Meg Bourbonniere \\ University of Pennsylvania School of Nursing \\ Neville E. Strumpf \\ University of Pennsylvania School of Nursing \\ Lois K. Evans \\ University of Pennsylvania School of Nursing \\ Greg Maislin \\ University of Pennsylvania School of Medicine
}

Follow this and additional works at: https://jdc.jefferson.edu/nursfp

Part of the Nursing Commons

Let us know how access to this document benefits you

\section{Recommended Citation}

Bourbonniere, Meg; Strumpf, Neville E.; Evans, Lois K.; and Maislin, Greg, "Organizational characteristics and restraint use for hospitalized nursing home residents." (2003). College of Nursing Faculty Papers \& Presentations. Paper 27.

https://jdc.jefferson.edu/nursfp/27

This Article is brought to you for free and open access by the Jefferson Digital Commons. The Jefferson Digital Commons is a service of Thomas Jefferson University's Center for Teaching and Learning (CTL). The Commons is a showcase for Jefferson books and journals, peer-reviewed scholarly publications, unique historical collections from the University archives, and teaching tools. The Jefferson Digital Commons allows researchers and interested readers anywhere in the world to learn about and keep up to date with Jefferson scholarship. This article has been accepted for inclusion in College of Nursing Faculty Papers \& Presentations by an authorized administrator of the Jefferson Digital Commons. For more information, please contact: JeffersonDigitalCommons@jefferson.edu. 


\author{
As submitted to: \\ Journal of the American Geriatrics Society \\ And later published as: \\ “ORGANIZATIONAL CHARACTERISTICS AND RESTRAINT USE \\ FOR \\ HOSPITALIZED NURSING HOME RESIDENTS" \\ Volume 51, Issue 8, 1 August 2003, Pages 1079-1084 \\ DOI: 10.1046/j.1532-5415.2003.51355.x
}

Meg Bourbonniere, RN, PhD

Neville E. Strumpf, PhD, RN, C, FAAN

Lois K. Evans, DNSc, RN, FAAN

University of Pennsylvania School of Nursing

Greg Maislin, MS, MA

University of Pennsylvania School of Medicine

Supported by the National Institute of Nursing Research 1 F31 NR07532-01

and by the National Institute on Aging R01 AG08324

Presented at the Gerontological Society of America Annual Meeting, November 2001

Address correspondence to:

Dr. Bourbonniere 
Center for Gerontology and Health Care Research

Brown University

Box G-ST311

Providence, RI 02912

Phone: 401-863-9958

Fax: 401-863-9219

Meg_Bourbonniere@Brown.edu 


\section{ABSTRACT}

Objectives: To examine the impact of organizational characteristics on physical restraint use for hospitalized nursing home residents.

Design: Secondary analysis of data obtained between 1994-1997 in a prospective phase lag design experiment using an advanced practice nurse (APN) intervention aimed at reducing physical restraint for a group of hospitalized nursing home residents.

Setting: Eleven medical and surgical units in one 600-bed teaching hospital.

Participants: 174 nursing home residents ranging in age from 61 to 100 years, hospitalized for a total of 1085 days.

Measurements: Physical restraint use, APN intervention, age, perceived fall risk, behavioral phenomena, perceived treatment interference, mental state, severity of illness, day of week, patientregistered nurse $(\mathrm{RN})$ ratio, patient-total nursing staff ratio, and skill mix.

Results: Controlling for the APN intervention, age, and patient behavioral characteristics (all of which increased the likelihood of restraint use), weekend days as an organizational characteristic significantly increased the odds of restraint. (Weekend day and patient-RN ratio on physical restraint use: OR: 1.92, 95\% CI: 1.38, 2.68, P<.001; Weekend day and patient-total staff ratio on physical restraint use: OR: 1.91, 95\% CI: 1.37, 2.66, P<.001; Weekend day and skill mix on physical restraint use: OR: 1.91, 95\% CI: $1.37,2.67, \mathrm{P}<.001)$.

Conclusions: Key findings suggest that organization of hospital care on weekends and patient characteristics that affect communication ability, such as severely impaired mental state, English as a second language, sedation, or sensory-perceptual losses, may be overlooked variables in restraint use.

\section{Key words: physical restraint; hospital care; health services}


Although use of physical restraints in nursing homes is highly regulated, such use in hospitals, other than psychiatric units, has received less scrutiny. ${ }^{1,2}$ Over the past ten years, federal agencies and professional organizations have advocated the reduction or elimination of physical restraints in acute care. ${ }^{3-5}$ Practices and outcomes of physical restraint in hospital settings have been identified as research priorities. ${ }^{6}$ The extent of physical restraint use in hospitals, however, remains unknown because no formal regulatory mechanism for tracking prevalence exists. The few studies of physical restraint use in hospitals indicate a prevalence rate ranging from $3.4 \%$ to $18.5 \%$, with adults over the age of 65 more frequently restrained. ${ }^{7-13}$ For hospitalized nursing home residents, the rate can be as high as $60 \% .^{14}$

Physical restraint use has been linked to higher mortality and morbidity. ${ }^{8,9,11,12}$ Adverse events associated with hospital restraint use include reduction or alteration in physical and psychological function, increased resource use, and heightened potential for injury. $9,11,12,15,16$ The research literature on restraint use in hospitals provides little documentation on injuries and deaths, although such events are noted for nursing homes. ${ }^{17}$

Restraint use in acute care is generally attributed to patient or organizational characteristics. Patient characteristics that increase the likelihood of restraint use include age greater than 70 years, cognitive impairment, behavioral phenomena, reduced physical function, and severity of illness. ${ }^{7-9,11,12}$ These are also common characteristics among nursing home residents. Risk factors for restraint use specifically associated with care in hospital settings include nursing assessment of fall risk, presence of medical devices restricting mobility, use of major tranquilizers, and surgery. ${ }^{7,11,12}$ 
Organizational characteristics play an important role in the use of physical restraints because of the continuous interactions among patients, systems, and caregiving staff. Nurses are most often the personnel who initiate restraint use, ${ }^{8,11,15,18-21}$ and do so for reasons of patient safety mostly associated with fall risk, treatment interference, and behavioral phenomena. ${ }^{7,10,11,13,19-21}$ Restraint use occurs despite any substantive link between restraint use and prevention of injury. ${ }^{6,22}$

Anecdotal reports imply that hospital unit staffing levels may explain interinstitutional differences with regard to restraint use. ${ }^{10,13}$ Nurses consistently cite understaffing or inability to provide appropriate patient observation as reasons for restraint use. ${ }^{15,18,20,23-25}$ Families and student nurses share these concerns. $^{26,27}$

Understaffing is a consistent theme in the literature on restraint use in hospitals. ${ }^{12,19,28,29}$ Although a recent study investigated the relationship between restraint use and staffing, results were reported at the hospital level, aggregated across 10 hospitals in an integrated system, and failed to include patient characteristics. ${ }^{30}$ Thus, the relationship between hospital staffing and restraint use has never been subjected to careful examination at the unit level. The incidence of physical restraint may be an artifact of time of day during which data were collected or the method of data collection. Restraint data are usually prospectively collected when unit staffing levels are at their highest or at times of less than peak demand on staff. Alternatively, retrospective chart review is used and little research supports the reliability of this method. Thus, the usage of physical restraints may actually be underreported. ${ }^{8,13}$ Restraint use at night, on weekends, and on holidays, when staffing levels are lower and conceivably restraint use may be higher, is rarely observed or recorded. The purpose of this study was to examine the 
impact of organizational characteristics on physical restraint use in hospitalized nursing home residents over the course of an entire hospital stay. 


\section{METHODS}

\section{Data Source}

This study was a secondary analysis of data obtained in a prospective phase lag design experiment to examine the effects of an advanced practice nurse (APN) intervention on the reduction of physical restraints in hospitalized nursing home residents. Resident/patients were admitted from one nursing home to 11 medical-surgical units of one urban medical center for treatment of a variety of acute illnesses or injuries. Patients in Phase I received usual hospital care, while those in Phase II received an assessment by the study APN who then consulted with their assigned caregivers on ways to avoid restraining the patient. Coincidental with the onset of Phase II of the study, and not a part of the parent study design, was a work redesign at the study hospital. This resulted in structural changes to the physical plant, realignment of physician practice groups, consolidation of patient care units, and changes in registered nurse $(\mathrm{RN})$ roles. Although findings from the parent study demonstrated that the APN intervention significantly reduced daily restraint use (proportion of days restrained per length of hospital stay), the intervention did not produce the expected effect of overall reduction of restraint use (the prevalence of physical restraint). ${ }^{31}$

Concurrent events associated with work redesign conceivably influenced these outcomes, diluting the expected results of the APN intervention. In an effort to examine these data more closely, this present study used data from patients enrolled in both phases of the parent study to explore the relationship between RN staffing and physical restraint use. Data were stripped of identifying information to insure confidentiality of the residents. This study received approval from the University of Pennsylvania's Institutional Review Board. For purposes of analysis, the research question was: what patient-specific (age, mental state, severity of illness, behavioral phenomena, fall risk, and treatment interference) and 
organizational (day of week [weekday vs. weekend day], unit level patient-RN ratios, unit level patienttotal nursing staff ratios, and unit level percentage of RN staffing) characteristics predicted daily restraint use for hospitalized nursing home residents?

\section{Measures}

Physical restraint was defined as any device intended to limit freedom of movement and free access to one's body, and included chest/vest, wrist or ankle ties, mitt, belt, crotch/pelvic device, suit/harness, sheet, or geriatric or recliner chair with fixed tray table for purposes other than eating or any desired activities. The research assistant or the APN determined the presence of any restraint devices on a daily basis by direct observation of the patient. Restraint status was confirmed with the primary nurse and review of the hospital medical record daily throughout hospitalization, including weekends and holidays.

\section{Patient Characteristics}

At least every other day during hospitalization, each patient's primary nurse was asked to: 1) rate his/her perceptions of the patient's fall risk from bed, chair, wheelchair, and when walking as high, medium, or

low/none; 2) assess behavioral phenomena by completing the Nursing Home Behavior Problem Scale; ${ }^{32}$ and 3) rate the frequency of perceived treatment interference (e.g., self-removal or threat of self-removal of devices used in diagnosis, treatment, or monitoring) for each treatment used in the patient's care according to a 6-point scale, ranging from $0=$ not applicable to $5=$ constantly. The Mini-Mental State Exam (MMSE) ${ }^{33}$ was administered at least every other day by the research assistant; when scores were not obtained, the reason was noted. Mental state impairment was then categorized as severe (MMSE 011), moderate (MMSE 12-19), mild to none (MMSE 20-30), refused/severe confusion (e.g., patient or family declined interview, patient was confused and would not respond, or patient had dementia 
diagnosis and would not talk to interviewer), and communication barrier/acute condition (e.g., patient was unresponsive [sedated, sleeping, comatose], had shortness of breath, aphasia, hearing or vision loss and aids were unavailable, or spoke no English). Severity of illness was derived from a combined score of admission functional level and the medical comorbidity score using the Charlson prognostic

taxonomy. ${ }^{34}$ Hospital admission records were reviewed by the research assistant, who scored functional status on a 4-point scale ( $0=$ fully independent/no difficulty to $3=$ totally dependent $/ 2$ person assist) and assigned appropriate weights to each of 19 comorbid conditions, if present.

\section{Organizational Characteristics}

Day of the week was determined for each day of a patient's hospital stay. The variable was then dichotomized as weekend day (Saturday or Sunday) or otherwise. Daily staffing measures of patientregistered nurse $(\mathrm{RN})$ ratios, patient-total nursing care staff ratios, and skill mix were also obtained for each day of a patient's hospital stay. Unit census and numbers of direct patient care staff were obtained for each 8-hour shift. Three shift scores for each staffing measure were averaged over each 24-hour period. Patient-RN ratios (PT-RN) were determined by dividing the number of patients on each patient's hospital unit by the number of RNs in direct patient care. Scores indicate the daily average number of patients for whom each RN was responsible. Patient to total nursing care staff ratios (PT-TOT) were determined by dividing the number of patients on each patient's hospital unit by the total number of direct care nursing staff. Scores indicated the theoretical distribution of the daily average number of patients to staff. Skill mix (\%RN) was determined by dividing the total number of RNs providing direct patient care by the total number of direct care nursing staff for each hospital unit where patients were receiving care. Scores indicated the percentage of RN staff available to provide care as a portion of the total unit staff. 


\section{Analysis}

Data were analyzed using SAS version 8.1. ${ }^{35}$ Staffing variables were calculated using Microsoft Excel ${ }^{36}$ and imported to SAS. Data collected less than daily were imputed by forward- and back-filling data using SAS. We assumed that resident/patient scores remained constant from the initial measurement back to the date of admission and forward to the next point of measurement for instances of multiple measures over time. Because the staffing variables were strongly correlated, three models were constructed to evaluate each independently using generalized estimating equations (GEE). Odds ratios (OR) and 95\% confidence intervals (CI) were derived. Statistical significance for all models was determined by an alpha of .05 . 


\section{RESULTS}

\section{Sample}

A total of 174 hospitalized nursing home residents had available data for this analysis. All were residents of a religiously affiliated nursing home facility and $100 \%$ were Caucasian. Table 1 presents a summary of patient characteristics. No residents consenting to participate, directly or through next of kin, were excluded; consequently, the sample included severely demented and non-English speaking frail older adults. Descriptive statistics for organizational characteristics are summarized in Table 2.

\section{Table 1. Hospitalized Nursing Home Resident (N=174) Characteristics}

$\begin{array}{lc}\text { Mean age (Standard Deviation; range) } & 84.8(7.0 ; 61.3-100) \\ \text { Gender (Female), n (\%) } & 118(67.8) \\ \text { Ever restrained in hospital, n (\%) } & 47(27) \\ \text { Advanced Practice Nurse intervention, n (\%) } & 94(54) \\ \text { Mean Charlson Index (Standard Deviation; range) } & 3.8(1.8 ; 0-11) \\ \text { Admission functional status } & 3(1.7) \\ \text { Fully independent, n (\%) } & 0(0) \\ \text { Needs verbal reminder, n (\%) } & 29(16.7) \\ \text { Needs minimum-moderate assistance, n (\%) } & 142(81.6) \\ \text { Totally dependent/2 person assist, n (\%) } & 6.6(2.0 ; 0-14) \\ \text { Mean Severity of Illness (Standard Deviation; range) } & 13.8(8.2 ; 0-30) \\ \text { Mean Mini-Mental State Exam (Standard Deviation; range) }\end{array}$


Lowest Mini-Mental State Exam score recorded for

resident/patient in hospital $(\mathrm{N}=171)$

Mini-Mental State Exam 0-11, n (\%) 51 (29.8)

Mini-Mental State Exam 12-19, n (\%) 30 (17.5)

Mini-Mental State Exam 20-30, n (\%) 20 (11.7)

Resident/patient refused/too confused, n (\%) $18(10.5)$

Communication barrier/acute condition, n (\%) $\quad 52(30.4)$

Mean Fall Risk Index (Standard Deviation; range) $6.7(2.3 ; 0-8)$

Mean Behavior Problem Scale (Standard Deviation; range) 2.5 (4.8; 0-32)

Treatment Interference (N=168), n (\%) $51(30.4)$

Mean length of stay in days (Standard Deviation; range) $6.2(3.5 ; 1-26)$

\section{Table 2. Organizational Characteristics ( $=1085$ days)}

\begin{tabular}{lc}
\hline Mean Patient-Registered Nurse ratio (Standard Deviation; range) & $6.7(1.9 ; 0.5-16)$ \\
Mean Patient-total nursing care staff (Standard Deviation; range) & $4.1(0.8 ; 0.4-7.7)$ \\
Mean \% Registered Nurse Skill Mix (Standard Deviation; range) & $0.7(0.2 ; 0.3-1.0)$ \\
Day of Week (weekend day) n (\%) & $297(27.4)$
\end{tabular}

For each model, Table 3 presents odds ratios and 95\% confidence intervals for all variables. Essentially, all three models produced consistent results. As expected for resident/patients who received the APN intervention, the risk of being restrained was significantly lower $(\mathrm{P}<.001, \mathrm{OR}=0.23, \mathrm{CI}=0.10,0.55$ [WE+PT-RN]; P<.001, OR=0.23, CI=0.10, 0.51 [WE+PT-TOT]; P=.001, OR=0.23, CI=0.10, 0.55 [WE+\%RN]). Mental state categories of severe impairment and communication barriers, or acute 
conditions that precluded mental state testing, increased the risk of restraint use, while other categories had no significant effects on the risk. Those who scored less than 12 on the MMSE had greater than 6 times the risk for restraint than those scoring 20 or higher $(\mathrm{P}=.019, \mathrm{OR}=6.27, \mathrm{CI}=1.35,29.18[\mathrm{WE}+\mathrm{PT}-$ $\mathrm{RN}] ; \mathrm{P}=.022, \mathrm{OR}=6.07, \mathrm{CI}=1.29,28.52$ [WE+PT-TOT]; P=.019, OR=6.15, $\mathrm{CI}=1.34,28.12$ [WE+\% RN]). Those categorized as having communication barriers or acute conditions preventing mental state testing were at similar risk for restraint $(\mathrm{P}=.046, \mathrm{OR}=6.10, \mathrm{CI}=1.03,35.99$ [WE+PT-RN]; $\mathrm{P}=.052, \mathrm{OR}=5.85, \mathrm{CI}=0.98,34.79$ [WE$+\mathrm{PT}-\mathrm{TOT}] ; \mathrm{P}=.046, \mathrm{OR}=5.99, \mathrm{CI}=1.03,34.84[\mathrm{WE}+\% \mathrm{RN}])$. Note that for WE+PT-TOT, the category was marginally significant. Certain patient characteristics significantly increased the risk of restraint: behavioral phenomena $(\mathrm{P}<.001, \mathrm{OR}=1.61, \mathrm{CI}=1.30,1.99$ [WE+PT-RN]; P<.001, OR=1.60, CI=1.29, 1.98 [WE+PT-TOT]; P<.001, OR=1.61, CI=1.30, 2.00 $[\mathrm{WE}+\% \mathrm{RN}])$ and treatment interference $(\mathrm{P}<.001, \mathrm{OR}=2.49, \mathrm{CI}=1.96,3.15[\mathrm{WE}+\mathrm{PT}-\mathrm{RN}] ; p<0.001$, $\mathrm{OR}=2.49, \mathrm{CI}=1.98,3.14[\mathrm{WE}+\mathrm{PT}-\mathrm{TOT}] ; \mathrm{P}<.001, \mathrm{OR}=2.49, \mathrm{CI}=1.96,3.16[\mathrm{WE}+\% \mathrm{RN}])$.

The strongest hospital characteristic associated with restraint use was being in the hospital on a weekend $(\mathrm{P}<.001, \mathrm{OR}=1.92, \mathrm{CI}=1.38,2.68$ [WE+PT-RN]; $\mathrm{P}<.001, \mathrm{OR}=1.91, \mathrm{CI}=1.37,2.66$ [WE+PT-TOT]; $\mathrm{P}<.001, \mathrm{OR}=1.91, \mathrm{CI}=1.37,2.67[\mathrm{WE}+\% \mathrm{RN}])$. Despite a significant bivariate correlation $(r=.07)$ with physical restraint use, WE+PT-RN retained no relationship to restraint use in any of the full models. 
Table 3. Comparison of Models of the Effects of Characteristics Associated with Physical Restraint Use Among

\section{Hospitalized Nursing Home Residents}

\begin{tabular}{|c|c|c|c|c|c|c|}
\hline \multirow[t]{3}{*}{ Parameter } & \multicolumn{2}{|c|}{ Day of Week + Patient-RN Ratio } & \multirow{2}{*}{\multicolumn{2}{|c|}{$\begin{array}{l}\text { Day of Week + Patient-Total } \\
\text { Staff Ratio }\end{array}$}} & \multicolumn{2}{|c|}{ Day of Week + Skill Mix } \\
\hline & & & & & & \\
\hline & OR $(95 \% \mathrm{CI})$ & $\mathrm{P}$-value & OR $(95 \% \mathrm{CI})$ & $\mathrm{P}$-value & OR $(95 \% \mathrm{CI})$ & $\mathrm{P}$-value \\
\hline APN Intervention & $0.23(0.10,0.55)$ & $<.001$ & $0.23(0.10,0.51)$ & $<.001$ & $0.23(0.10,0.55)$ & .001 \\
\hline Age & $1.48(0.82,2.69)$ & .198 & $1.47(0.82,2.63)$ & .192 & $1.49(0.83,2.68)$ & .184 \\
\hline MMSE 0-11 & $6.27(1.35,29.18)$ & .019 & $6.07(1.29,28.52)$ & .022 & $6.15(1.34,28.12)$ & .019 \\
\hline MMSE 12-19 & $3.33(0.77,14.48)$ & .108 & $3.16(0.73,13.81)$ & .126 & $3.26(0.76,13.94)$ & .112 \\
\hline MMSE refused & $3.60(0.72,18.15)$ & .120 & $3.41(0.67,17.42)$ & .140 & $3.54(0.71,17.56)$ & .122 \\
\hline MMSE & $6.10(1.03,35.99)$ & .046 & $5.85(0.98,34.79)$ & .052 & $5.99,(1.03,34.84)$ & .046 \\
\hline \multicolumn{7}{|l|}{ communication } \\
\hline \multicolumn{7}{|l|}{ barrier/acute } \\
\hline \multicolumn{7}{|l|}{ condition } \\
\hline Behavior Problem & $1.61(1.30,1.99)$ & $<.001$ & $1.60(1.29,1.98)$ & $<.001$ & $1.61(1.30,2.00)$ & $<.001$ \\
\hline \multicolumn{7}{|l|}{ Scale } \\
\hline Fall Risk Index & $0.90(0.74,1.08)$ & .243 & $0.90(0.75,1.08)$ & .265 & $0.90(0.74,1.08)$ & .249 \\
\hline
\end{tabular}


Treatment

Interference

Severity of Illness

Weekend

Patient-RN Ratio

Patient-Total Staff

Ratio

Skill Mix
$2.49(1.96,3.15)$

$0.92(0.59,1.43)$

$1.92(1.38,2.68)$

$0.94(0.74,1.19)$

.881

.695

$0.93(0.60,1.43)$

.735

$<.001$

$1.91(1.37,2.66)$

$<.001$

.612

$$
1.01(0.85,1.21)
$$

$2.49(1.96,3.16) \quad<.001$

$0.92(5.92,1.43)$

.711

$1.91(1.37,2.67)$

$<.001$ 


\section{DISCUSSION}

The strength of this analysis rests on an examination of organizational characteristics at the patient level over the course of a hospital stay on a medical-surgical unit. As a secondary analysis, it was limited by a finite set of variables or measures to assess restraint use, and the related patient and organizational characteristics. The use of daily averages for staffing and census, a non-traditional way of measuring hospital unit staffing, may also be considered a limitation of this secondary analysis. In practice and research, the traditional method of measuring hospital staffing is by hours worked per patient day. Typically, all types of nursing unit personnel, including indirect care providers, are aggregated to the unit, hospital, or system level. The measure then determines the number of paid hours (less vacation, holiday, and sick hours) and divides the resulting hours worked by the number of patient days for a defined period of time. Recognizing that this traditional method fails to capture actual unit census and numbers of direct patient care staff, we thus calculated our patient-registered nurse and total nursing care staff ratios as described earlier. We believe our average daily measures more closely approximated what occurred in day-to-day hospital practice during the study period.

The rate of physical restraint in this study, nearly $28 \%$, should pose a major concern to health care providers, patients, families, and hospital administrators. Although this rate falls within the range established in the literature, it is worrisome for two reasons. First, most of the hospital restraint research was conducted before the initiation in 1994 of the parent study used for this analysis. Thus, patient responses to restraint use, predictors of restraint use, and consequences of restraint use had already been documented. Second, during the past decade, federal agencies, accrediting bodies, and professional organizations have influenced the emergence of new care 
standards that emphasize elimination or reduction of physical restraints, including in hospitals. Comparison with current rates, however, is limited by the available data. The most recent prospective study in which restraint use was observed and reported noted a 59\% rate of restraint use for persons aged 65 years or older. This study, however, did not differentiate between acute and critical care. ${ }^{10}$

Behavioral phenomena and treatment interference continue to be strongly associated with restraint use. Categories of mental state impairment that significantly increased the odds of restraint (severe impairment and communication barriers or acute conditions that preclude mental state testing) provide further insight into the complexity of care faced by clinicians in acute care settings. Hospitalized older adults with these characteristics are very vulnerable for restraint use. Furthermore, the findings suggest that creative interventions must be designed and tested to allow clinicians to discover and provide for a variety of cultural or unspoken patient needs.

This study provided a unique opportunity to examine outcomes in a hospital re-engineering environment, about which little is currently known. The APN intervention reduced restraints for hospitalized nursing home residents despite a chaotic work environment with wide variations in patient-RN ratios, patient-total nursing staff ratios, and skill mix. Although hospital level patientstaff ratios and skill mix have predicted patient outcomes in other studies, ${ }^{29,37-39}$ this was the first study to examine unit level staffing data in relation to restraint use. The finding that the APN had an effect, and not unit level staffing, further underscores that APN consultation/intervention may be a useful strategy to improve outcomes among high-risk, vulnerable older adults. ${ }^{40}$ 
Organization of care on weekends strongly affected restraint use in this study, and may be an overlooked variable in hospital studies. Clinicians intuitively understand the challenges presented on weekends. Little formal evidence exists, however, to document greater patient vulnerability on weekends. Nevertheless, one notable exception recently appeared in the literature. In an interview just prior to his death, Dr. Avedis Donabedian used his personal experiences as an elderly patient with complex needs to characterize hospital floors as disastrous. ${ }^{41}$ Discontinuity of nursing care, attributed to the use of part-time employees and variable hours, and poorly oriented nurses working mainly on weekends, were among his major points. The number of new, float, or agency staff, overtime hours worked, new patient admissions or transfers on weekends, nursing workload, and availability of support services are factors that need to be examined to better understand changes in the organization of hospital care on weekends. A study of unit level measures of environmental stability, restraint use, and staffing variables would be important evidence in determining appropriate staffing and organizational milieu, and be a critical basis for any consideration of new models of care in contemporary acute care practice. This is especially true for very vulnerable nursing home residents who are transferred to the hospital, a milieu strikingly different from the one where most of their care is rendered. 


\section{REFERENCES}

1. HCFA announces new restraint regulation. Quality Care Advocate June/July, 1999; 1,5.

2. Mion LC. Establishing alternatives to physical restraints in the acute care setting: A conceptual framework to assist nurses' decision making. AACN Clinical Issues 1996; 7:592-602.

3. Weick MD. Physical restraints: An FDA update. Am J Nurs 1992;92:74-76, 78, 80.

4. Joint Commission on Healthcare Organizations. Restraint and seclusion standards plus scoring: Standards TX.7.1-TX.7.1.3.3. 1996 Comprehensive Accreditation Manual for Hospitals. Oakbrook Terrace, IL: Joint Commission on Healthcare Organizations; 1996.

5. American Nurses Association (ANA). Testimony of the ANA before the Restraint Task Force Joint Commission on the Accreditation on Healthcare Organizations. Washington, DC; 1997. 6. Mion LC, Minnick A, Palmer R. Physical restraint use in the hospital setting: Unresolved issues and directions for research. Milbank Q 1996;74:411-433.

7. Berland B, Wachtel TJ, Kiel DP, et al. Patient characteristics associated with the use of mechanical restraints. J Gen Intern Med 1990;5:480-485.

8. Frengley JD, Mion LC. Incidence of physical restraints on acute general medical wards. J Am Geriatr Soc 1986;34:565-568.

9. Lofgren RP, MacPherson DS, Granieri R, et al. Mechanical restraints on the medical wards: Are protective devices safe? Am J Public Health. 1989;79:735-738.

10. Minnick AF, Mion LC, Leipzig R, et al. Prevalence and patterns of physical restraint use in the acute care setting. J Nurs Adm 1998;28(11):19-24.

11. Mion LC, Frengley, JD, Jakovcic CA, et al. A further exploration of the use of physical restraints in hospitalized patients. J Am Geriatri Soc 1989;37:949-956. 
12. Robbins LJ, Boyko E, Lane J, et al. Binding the elderly: A prospective study of the use of mechanical restraints in an acute care hospital. J Am Geriatr Soc 1987;35:290-296.

13. Whitehead C, Finucane P, Henschke P, et al. Use of patient restraints in four Australian teaching hospitals. J Qual Clin Pract 1997;17:131-136.

14. Sullivan-Marx EM. Achieving restraint-free care of acutely confused older adults. J Gerontol Nurs 2000;27(4):56-61.

15. Strumpf, NE, Evans, LK. Physical restraint of the hospitalized elderly: Perceptions of patients and nurses. Nurs Res 1988;37:132-137.

16. Sullivan-Marx E, Baumgarten M, Strumpf N, et al. Physical restraint use among hospitalized nursing home residents with hip fracture. Gerontologist 1998;38(Special Issue 1):247.

17. Miles SH, Irvine P. Deaths caused by physical restraints. Gerontologist 1992;32:762-766.

18. Bryant H, Fernald L. Nursing knowledge and use of restraint alternatives: Acute and chronic care. Geriatr Nurs 1997; 18:57-60.

19. Macpherson DS, Lofgren RP, Granieri R, et al. Deciding to restrain medical patients. J Am Geriatr Soc 1990;38:516-520.

20. Molassiotis A, Newell R. Nurses' awareness of restraint use with elderly people in Greece and the U. K.: A cross-cultural pilot study. Int J Nurs Stud 1996;33:201-211.

21. Whitman GR, Davidson LJ, Rudy EB, et al. Practice patterns related to mechanical restraint use across a multi-institutional health care system. Outcomes Manag Nurs Pract 2001;5:102-109. 22. Evans, LK, Strumpf NE. Myths about elder restraint. Image J Nurs Sch 1990;22:124-128. 23. Maruschock RG. Evaluation of a hospital staff's knowledge regarding the use of physical restraint. J Nurs Staff Devel 1996;12:144-148. 
24.Matthiesen V, Lamb KV, McCannJ, et al. Hospital nurses' views about physical restraint use with older patients. J Gerontol Nurs 1996;22(6):8-16.

25. Murray J, Cott C. Nursing staff perceptions of the use and reduction in the use of physical restraints. Perspect 1998;22(1):2-10.

26. Kanski GW, Janelli LM, Jones HM, et al. Family reactions to restraints in an acute care setting. J Gerontol Nurs 1996;22(6);17-22.

27. Fradkin M, Kidron D, Hendel T. Istraeli student nurses' attitudes about physical restraints in acute care settings. Geriatr Nurs 1999;20:101-105.

28. Pham PQ. Housestaff attitudes towards the use of physical restraint. J Am Geriatr Soc 2001;49:S99.

29. Sullivan-Marx EM, Maislin G, Carson J. Hospital staffing, physical restraint, and patient outcomes. J Am Geriatr Soc 2001:49:S9.

30. Whitman GR, Davidson LJ, Sereika SM, et al. Staffing and pattern of mechanical restraint use across a multiple hospital system. Nurs Res 2001;50:356-362.

31. Strumpf N, Evans L, Capezuti E, et al. The effects of an advanced practice nurse intervention on physical restraint use among hospitalized nursing home residents. Gerontologist 1998;38(Special Issue 1):247.

32. Ray W, Taylor J, Lichtenstein M. The nursing home behavior problem scale. J Gerontol 1992;47:M9-M16.

33. Folstein M, Folstein S, McHugh P. Mini-mental state: A practical method for grading the cognitive state of patients for the clinician. J Psychiatr Res 1975;12:189-198.

34. Charlson M, Pompei P, Ales K, et al. A new method of classifying prognostic comorbidity in longitudinal studies: Development and validation. J Chronic Dis. 1992;40:373-383. 
35. SAS, version 8.1. SAS Institute. Cary, NC.

36. Excel. Microsoft Corporation. Redmond, WA; 1997.

37. Aiken LH, Lake ET, Semaan S, et al. Nurse practitioner managed care for persons with HIV infection. Image J Nurs Schol 1993;25:172-177.

38. Kovner, C, Gergen PJ. Nurse staffing levels and adverse events following surgery in U. S. hospitals. J Nurs Sch 1998;30:315-321.

39. Sovie MD, Jawad AF. Hospital restructuring and its impact on outcomes. J Nurs Adm 2001;31:588-600.

40. Wanich C, Sullivan-Marx EM, Gottlieb G, et al. Functional status outcomes of a nursing intervention in hospitalized elderly. J Nurs Schol 1992;24:449-452.

41. Mullan F. A founder of quality assessment encounters a troubled system firsthand. Health Aff 2001;20:137-141. 